\title{
Citation:
}

Bertone, E., Burford, M. A., \& Hamilton, D. P. (2018). Fluorescence probes for real-time remote cyanobacteria monitoring: a review of challenges and opportunities. Water Research, DOI:10.1016/j.watres.2018.05.001

\section{Fluorescence probes for real-time remote cyanobacteria monitoring: a review of challenges and opportunities}

Edoardo Bertone $^{\mathrm{a}, \mathrm{b}} *$, Michele A. Burford ${ }^{\mathrm{c}}$, David P. Hamilton ${ }^{\mathrm{c}}$

${ }^{a}$ Griffith School of Engineering and Built Environment, Griffith University, Parklands Drive, Southport, Queensland 4222, Australia

${ }^{b}$ Cities Research Institute, Griffith University, Parklands Drive, Southport, Queensland 4222, Australia

*Corresponding author: edoardo.bertone@griffithuni.edu.au

${ }^{c}$ Australian Rivers Institute, Griffith University, Kessels Road, Nathan, Queensland 4111, Australia

\begin{abstract}
In recent years, there has been a widespread deployment of submersible fluorescence sensors by water utilities. They are used to measure diagnostic pigments and estimate algae and cyanobacteria abundance in near real-time. Despite being useful and promising tools, operators and decision-makers often rely on the data provided by these probes without a full understanding of their limitations. As a result, this may lead to wrong and misleading estimations which, in turn, means that researchers and technicians distrust these sensors. In this review paper, we list and discuss the main limitations of such probes, as well as identifying the effect of environmental factors on pigment production, and in turn, the conversion to cyanobacteria abundance estimation. We argue that a comprehensive calibration approach to obtain reliable readings goes well beyond manufacturers' recommendations, and should involve several context-specific experiments. We also believe that if such a comprehensive set of experiments is conducted, the data collected from fluorescence sensors could be used in artificial intelligence modelling approaches to reliably predict, in near real-time, the presence and abundance of different cyanobacteria species. This would have significant benefits for both drinking and recreational water management, given that cyanobacterial toxicity, and taste and odour compounds production, are species-dependent.
\end{abstract}

Keywords: Artificial Intelligence; Cyanobacteria; Fluorescence; Remote sensors; Water quality; Water resources management 
Cyanobacteria are considered to be among the most interesting organisms for ecological and phycological studies (Beutler et al. 2003), in addition to being some of the oldest organisms on Earth. They are primary producers and some of them produce toxins and/or taste and odour compounds (Carmichael 2001, Schopf 1996, Waterbury et al. 1979). There is evidence to suggest that climate change may increase the frequency and magnitude of cyanobacterial blooms (O’Neil et al. 2012).

Submersible fluorescence sensors can rapidly provide an estimate of the biomass of algae, including cyanobacteria. Studies have shown that sensors correlate well with algal and cyanobacterial biomass measures in laboratory experiments, and thus they have been recommended as sensitive tools for realtime in-situ water management (Bastien et al. 2011, Brient et al. 2008, Gregor and Maršálek 2004). However, there have been challenges with the calibration of these sensors, particularly in highly turbid environments, or when species composition changes rapidly, either spatially or temporally. The use of remote fluorescence instrumentation, combined with curve-fitting techniques, provides a possible means to determine the presence of different groups of algae in a sample (Hodges et al. 2017). The premise for this application, however, is that the fluorescence excitation spectra must be constant for each algal species (Beutler et al. 2002). This appears to be the case for algal groups, typically referred to by researchers studying algal fluorescence as green (chlorophytes), brown (predominantly diatoms, dinoflagellates and golden brown flagellates), or mixed algal assemblages (Beutler et al. 2002). However in the case of cyanobacteria (referred to as the blue group), the spectrum changes with environmental conditions (Beutler et al. 2003). This not only hinders the ability to differentiate different cyanobacterial species, but also undermines the reliability of such probes in estimating the total biomass of cyanobacteria. Therefore environmental and technological interferences need to be accounted for.

This review examines environmental factors and technological limitations that can affect both the cyanobacterial spectra, and accurate measurement of biomass with commonly available in-situ fluorescence probes. If these factors can be accounted for, such tools would provide a more reliable means of monitoring blooms. In addition, the use of algorithms and models derived from fluorescence sensors' data could be used to provide estimates about which cyanobacterial species are likely to be present, with links to the prediction of the risk of presence of toxins, or taste and odour compounds.

This review firstly examines how environmental factors affect the pigment content of algal species. These factors complicate the conversion of probe readings to cyanobacterial biomass. Next, the technical constraints hindering an accurate reading, and inherent interferences made in the fluorescence measurements, are examined. The second part of the review assesses the feasibility of rapidly estimating the relative contribution of different species to the total biomass, as well as predicting toxin or taste and odour risks. Table 1 provides a list of the relevant literature analysed and cited based on the topic discussed.

\section{Table 1 - List of relevant references based on topic}

\begin{tabular}{|l|l|}
\hline Topic & Relevant literature cited \\
\hline Environmental & Bryant (1982) \\
interferences: & Alpine and Cloern (1985) \\
Chlorophyll-a & Everitt et al. (1990) \\
and & Lee et al. (1995) \\
& Mackey et al. (1996) \\
\hline
\end{tabular}




\begin{tabular}{|c|c|}
\hline $\begin{array}{l}\text { phycocyanin } \\
\text { yields }\end{array}$ & $\begin{array}{l}\text { Henrion et al. (1997) } \\
\text { MacColl (1998), Rapala (1998) } \\
\text { Beutler et al. (2002) } \\
\text { Beutler et al. (2003) } \\
\text { Izydorczyk et al. (2005) } \\
\text { Bryant (2006) } \\
\text { Pemberton et al. (2007), Seppälä et al. (2007), Gregor et al. (2007) } \\
\text { Brient et al. (2008), Randolph et al. (2008) } \\
\text { Millie et al. (2010), Ziegmann et al. (2010), Richardson et al. (2010) } \\
\text { Allan et al. (2011), McQuaid et al. (2011), Erickson et al. (2011) Bastien et } \\
\text { al. (2011) } \\
\text { NSW Office of Water (2012), Chang et al. (2012), Zamyadi et al. (2012) } \\
\text { Bowling et al. (2013), Horváth et al. (2013) } \\
\text { Sobiechowska-Sasim et al. (2014) } \\
\text { Kudela et al. (2015), Korak et al. (2015), Zieger (2015) } \\
\text { Hodges (2016b), Zamyadi et al. (2016a) } \\
\text { Hodges et al. (2017), Steiner et al. (2017), Kong et al. (2017) } \\
\text { McBride and Rose (in press) }\end{array}$ \\
\hline $\begin{array}{l}\text { Instrument } \\
\text { limitations and } \\
\text { opportunities }\end{array}$ & $\begin{array}{l}\text { Beutler et al. (1998) } \\
\text { Beutler et al. (2002) } \\
\text { Beutler et al. (2003) } \\
\text { Gregor and Maršálek (2004) } \\
\text { Seppälä et al. (2007), Pemberton et al. (2007), Gregor et al. (2007) } \\
\text { Brient et al. (2008) } \\
\text { Millie et al. (2010), Ziegmann et al. (2010), Richardson et al. (2010) } \\
\text { Pobel et al. (2011), Bastien et al. (2011), Dennis et al. (2011), Pomati et al. } \\
\text { (2011), Hashemi et al. (2011) } \\
\text { NSW Office of Water (2012) } \\
\text { Bowling et al. (2013), Horváth et al. (2013), Pomati et al. (2013) } \\
\text { Sobiechowska-Sasim et al. (2014) } \\
\text { Hamilton et al. (2015), Zieger (2015) } \\
\text { Zamyadi et al. (2016a), Bowling et al. (2016), Hodges (2016b), Zhou et al. } \\
\text { (2016) } \\
\text { McBride and Rose (in press) }\end{array}$ \\
\hline $\begin{array}{l}\text { Fluorescence } \\
\text { measurement } \\
\text { limitations }\end{array}$ & $\begin{array}{l}\text { Schreiber et al. (1995) } \\
\text { Asai et al. (2001) } \\
\text { Gregor and Maršálek (2004) } \\
\text { Kostoglidis et al. (2005) } \\
\text { Gregor et al. (2007), Seppälä et al. (2007) } \\
\text { Brient et al. (2008), Sackmann et al. (2008) } \\
\text { Millie et al. (2010) } \\
\text { McQuaid et al. (2011), Bastien et al. (2011), Hashemi et al. (2011) } \\
\text { Chang et al. (2012), Zamyadi et al. (2012) } \\
\text { Bowling et al. (2013) } \\
\text { Korak et al. (2015), Wang et al. (2015) } \\
\text { Zamyadi et al. (2016a), Hodges (2016b), Bowling et al. (2016) Watson et al. } \\
\text { (2016) }\end{array}$ \\
\hline
\end{tabular}




\begin{tabular}{|c|c|}
\hline & McBride and Rose (in press) \\
\hline $\begin{array}{l}\text { Estimating } \\
\text { proportion of } \\
\text { different algal } \\
\text { groups, classes, } \\
\text { species }\end{array}$ & $\begin{array}{l}\text { Gieskes et al. (1988) } \\
\text { Everitt et al. (1990) } \\
\text { Mackey et al. (1996) } \\
\text { Henrion et al. (1997) } \\
\text { Pinckney et al. (2001) } \\
\text { Izydorczyk et al. (2005) } \\
\text { Millie et al. (2010) } \\
\text { Bastien et al. (2011) } \\
\text { Zieger (2015) } \\
\text { Kpodonu et al. (2016), Zamyadi et al. (2016a) } \\
\text { van der Linden et al. (2017) }\end{array}$ \\
\hline $\begin{array}{l}\text { Predicting taste } \\
\text { and odour and } \\
\text { toxicity risk }\end{array}$ & $\begin{array}{l}\text { Hawkins et al. (2001) } \\
\text { Vézie et al. (2002) } \\
\text { Rohrlack et al. (2008), Henderson et al. (2008) } \\
\text { Everson et al. (2009) } \\
\text { Chapman (2010), Ziegmann et al. (2010) } \\
\text { American Water Works Association (2011), Bastien et al. (2011) Everson et } \\
\text { al. (2011) } \\
\text { Li et al. (2012) } \\
\text { Leloup et al. (2013) } \\
\text { Kong et al. (2014), Wert et al. (2014) } \\
\text { Su et al. (2015), Wang et al. (2015), Korak et al. (2015) } \\
\text { Bertone and O’Halloran (2016), Willis et al. (2016) } \\
\text { Zamyadi et al. (2016a), (Zamyadi et al. 2016b), Watson et al. (2016) } \\
\text { Pivokonsky et al. (2016) }\end{array}$ \\
\hline $\begin{array}{l}\text { Relevant } \\
\text { artificial } \\
\text { intelligence } \\
\text { modelling } \\
\text { applications }\end{array}$ & $\begin{array}{l}\text { Jaynes (1957) } \\
\text { Maier and Dandy (2000), Wallace and Hamilton (2000), Singh (2000) } \\
\text { Tanyimboh and Sheahan (2002) } \\
\text { Embleton et al. (2003) } \\
\text { Castelletti and Soncini-Sessa (2007), Uusitalo (2007), Hamilton et al. (2007) } \\
\text { Fenton and Neil (2008), Lee and Wentz (2008) } \\
\text { Johnson et al. (2010) } \\
\text { Mosleh et al. (2012), Chen and Pollino (2012) } \\
\text { Bertone et al. (2015), Rigosi et al. (2015) } \\
\text { Bertone et al. (2016a), Bertone et al. (2016b) }\end{array}$ \\
\hline
\end{tabular}

\section{Environmental interferences: Chlorophyll-a and phycocyanin yields}

The functioning principle for estimating algal and, more specifically, cyanobacterial biomass using fluorometry relies on the determination of diagnostic pigments, with a focus on chlorophyll $a$ (chl-a), $b$ and $c$ and carotenoids, as well as phycobilins (such as phycocyanin and phycoerythrin).

Chlorophyll $a$, measured by in situ fluorometry, is a proxy for total algal biomass, as it is easy to calculate, and it is universally present in both prokaryotic and eukaryotic algae (Millie et al. 2010). Values have also been derived from water reflectance data monitored by satellites (Allan et al. 2011) and, along with other spectral data, were used to differentiate between two key cyanobacterial species 
(Kudela et al. 2015). However, typically chlorophyll fluorescence does not provide information on the algal community composition (Ziegmann et al. 2010). The closest that can be achieved in terms of community differentiation is at the algal class level using a range of excitation and emission fluorescence spectra, e.g., for green algae. In addition, many studies (e.g., Bowling et al. (2013), Brient et al. (2008), Pemberton et al. (2007)), have not been able to establish a strong correlation between cyanobacterial biovolume and chl-a measured by in-situ fluorometry.

Cyanobacteria contain phycobilisomes which absorb light in a different range to chl-a, i.e., between 550 and $650 \mathrm{~nm}$, expanding the range of wavelengths which may be available for photosynthesis (Bryant 2006, Korak et al. 2015). In particular, phycocyanin (PC) and phycoerythrin (PE) are two fluorescent phycobilisomes that can be used to quantify cyanobacterial biomass, with PC most commonly measured using on-line fluorescence probes. The advantage of using phycobilisomes is that: (1) they only occur in cyanobacteria, allowing differentiation from other algae; and (2) they fluoresce at higher wavelengths than dissolved organic matter (DOM), thus reducing interference from these compounds, provided quenching effects (discussed later) are accounted for. PC is generally preferred to PE because PC is produced by all cyanobacteria while PE is produced only by some species (Bryant 1982, 2006). However, PE is more prevalent in benthic cyanobacteria because they have light absorption wavelengths aligned with the spectrum for bottom waters, due to differential absorption of light through the water column, resulting in blue-green light exposure (Korak et al. 2015, MacColl 1998). Therefore PE could be useful for fluorescence probes specifically targeting benthic cyanobacterial detection.

All cyanobacterial species have a specific range of chl-a and PC contents (i.e., quota) per cell (Brient et al. 2008, Richardson et al. 2010, Seppälä et al. 2007, Sobiechowska-Sasim et al. 2014), usually proportional to the cell volume (Brient et al. 2008), and have different ratios of pigments (Ziegmann et al. 2010). Average cell volumes can be estimated based on species by using tables, databases and calculators readily available online (e.g. (DELWP)). Such averages can be subject to variations, with previous studies finding cell volumes considerably lower than values that have been reported in such commonly used standard cell size tables, especially in summer and autumn (NSW Office of Water 2012). Each cyanobacterial pigment has an excitation and emission spectrum, hence, based on spectral signature of a sample, it is possible to identify the different phycobilins and separate them from chl-a and other background signals (Seppälä et al. 2007). A summary table of pigment ratios, based on literature data, is provided in Mackey et al. (1996). Hodges (2016a) and Hodges et al. (2017), as well as Zamyadi et al. (2016a) also summarise several studies of pigment ratios for different species. Differences in pigment content and ratios arise because each species has a different cell size and geometry (Alpine and Cloern 1985, Lee et al. 1995). For instance, filamentous species, unlike unicellular species, might form dense clumps (especially in the field), producing nonlinear responses due to the surface cells absorbing a large portion of the light (Hodges 2016a). This is not always the case, however, since other studies involving blooms of filamentous species have shown a linear correlation between cyanobacterial biomass and PC fluorescence (Seppälä et al. 2007). Adding further complexity, pigment ratios within species are affected by light regimes, nutrients, physiological status (e.g. growth stage) and strain dominance, as well as other environmental conditions (Beutler et al. 2002, Mackey et al. 1996, Seppälä et al. 2007, Zamyadi et al. 2016a, Ziegmann et al. 2010). Therefore, although correlations between PC fluorescence and total cyanobacterial biovolume can be determined, they are usually applicable only to periods when there is a high proportion of cyanobacteria amongst the algal assemblage (e.g. Randolph et al. (2008); Brient et al. (2008), Hodges (2016a), McQuaid et al. (2011); Izydorczyk et al. (2005)). More sophisticated models are needed to account for the many potentially confounding factors that disrupt this relationship. 
Studies in the laboratory using traditional spectrophotometric analysis of cultures of Microcystis aeruginosa and Dolichospermum circinale have found the highest PC cell content during the exponential growth phase ( 0.004 and 0.018 RFU/cell respectively), with the content reduced by $50 \%$ during stationary phase (0.002 and $0.009 \mathrm{RFU} /$ cell respectively) (Chang et al. 2012). Other studies have shown that PC only dominates in the latter stages of growth (Ziegmann et al. 2010). This is consistent with Gregor et al. (2007), who determined that older cells have higher PC fluorescence. Other studies have found that the PC content is lowest when cyanobacteria growth rates are highest (Lee et al. 1995). Hence there is no agreement between studies on when PC content is likely to be higher, suggesting species and methodological differences in PC quotas. In addition, it is important to take into account the relationships between PC extraction efficiency and cyanobacteria concentrations, with previous studies showing how the PC/chl-a ratio often decreases in more diluted samples (Horváth et al. 2013).

Light history is also an important factor affecting pigment content of algae, including cyanobacteria (Erickson et al. 2011). PC content is often higher following exposure to low light (Gregor et al. 2007). This is because in low light environments, cells accumulate photosynthetic antenna pigments to allow them to capture more light, whilst when light is not limiting, the photosynthetic pigments are reduced to prevent excessive excitation energy and cell damage (Seppälä et al. 2007). Under high light intensities, non- photochemical quenching also occurs, leading to lower pigment fluorescence (McBride and Rose in press). These findings are also in line with Beutler et al. (2003), who showed that PC/chla ratios were higher at lower light intensities. Hence, in periods of high light intensity, surface cyanobacteria may produce less $\mathrm{PC}$, and thus a fluorometric probe reading could underestimate the cyanobacteria biomass. To avoid the issue, only night readings can be considered, while disregarding daytime measurements (McBride and Rose in press).

Despite these findings, there does not seem to be agreement on the effect of light intensity on PC production (Zamyadi et al. 2016a), with several other studies not finding any significant effect related to previous light exposure (Beutler et al. 2002, Brient et al. 2008, Zamyadi et al. 2012). Other studies have measured an increase in the fluorescence signal following exposure to ambient light compared to dimmed ambient light (Zieger 2015). Ambient light was also shown to result in higher PC yields for Aphanizomenon sp. (Hodges 2016a), recently renamed to Chrysosporum sp. Differences in PC content can also be found between natural and artificial light, suggesting that culture studies in the laboratory may lead to inaccurate results depending on the light intensities and spectra of the light source (Brient et al. 2008). The effect of irradiance seems to also be species-specific (Hodges 2016a), with the characteristic chl-a/marker pigment ratios affected by the history of light exposure (Everitt et al. 1990).

Nutrients can affect the pigment content of cells. For instance, a lack of nitrogen can lead to PC degradation in cyanobacterial cultures (Rapala 1998). Beutler et al. (2003) found that increasing phosphate and nitrate concentrations increased the PC/chl-a ratio in cyanobacteria. PC can also be released into the water during blooms, then rapidly degraded (Izydorczyk et al. 2005, Steiner et al. 2017). Differences between in-situ and laboratory experiments have also been noted, although some studies have found high similarity (Bastien et al. 2011, Brient et al. 2008, Hodges 2016a, Kong et al. 2017).

There are opportunities to estimate cyanobacteria composition from fluorescence emission spectrum patterns. Henrion et al. (1997) asserted that although the intensity of the fluorescence spectrum can change due to some of the factors outlined above, the pattern of the fluorescence spectrum does not change; thus principal component analysis of excitation-emission matrices (EEM) of surface water can be used to identify the cyanobacterial composition of the sample. Nevertheless, measuring EEM is time consuming (Ziegmann et al. 2010), compared to in-situ fluorescence probes. 
As outlined in Millie et al. (2010), the use of in-situ spectrometers and fluorometers has become common practice for water monitoring programs. In vivo fluorometers typically work by using a LED light source associated with a given volume of water in front of the optical window, and measuring the emitted fluorescence from excitation of phytoplankton cells using a detection filter located perpendicularly to the excitation source. Spectrofluorometric probes, through real-time monitoring, are a useful tool to detect rapid spatiotemporal changes in cyanobacterial biomass, compared to conventional low-frequency sampling (Hamilton et al. 2015, Pobel et al. 2011). In terms of accuracy, in-vivo fluorescence is typically less precise than extracted in vitro fluorescence (McBride and Rose in press), and fluorometric and spectrofluorometric methods are more sensitive than spectrophotometric measures (Millie et al. 2010, Sobiechowska-Sasim et al. 2014). Zamyadi et al. (2016a) have reviewed the available information on in-situ fluorescence instrumentation for cyanobacterial detection.

Fluorometric probes can have a number of advantages compared to other methods, e.g. online real-time lake profiling, and can provide a good estimate of the total cyanobacterial biovolume (Bowling et al. 2016). Despite this, the readings are affected by several interferences, and so far they cannot identify specific species (Zamyadi et al. 2016a). In addition, previous studies found that probe accuracy decreases when determining cell densities, rather than biovolume, due to the presence of heterogeneous mixtures of species with different cell sizes (Bastien et al. 2011, Bowling et al. 2016). Furthermore, the probes require reliable cleaning systems to guarantee consistent levels of accuracy and reliability over time (Brient et al. 2008, NSW Office of Water 2012). Some probes have also been found to be unable to detect fluorescence below certain lower thresholds (e.g. $2.6 \mu \mathrm{g} / \mathrm{L}$ (Hodges 2016a)). Some sensors also consistently underestimate cyanobacterial biomass (Bastien et al. 2011).

Issues can also arise due to the limitations of the manufacturer's machine calibration, which is typically performed using cell counts of a specific cyanobacterial species, e.g. Microcystis aeruginosa. Such species-specific calibration can be of limited use in any waterbody where a mix of species is present (Bowling et al. 2013, Hodges 2016a). One problem that needs to be overcome is the lack of proper laboratory-based PC determination methods, due to low PC extraction efficiency (Seppälä et al. 2007). More recently improved extraction methods have been demonstrated (Horváth et al. 2013). Calibration with different algal species with a range of biovolumes is recommended, as performed in Brient et al. (2008). Alternatively, a mixed assemblage, representative of the monitored site, can be used to relate fluorescence to a site-specific biovolume (McBride and Rose in press).

Several fluorescence devices have been developed in an attempt to characterize the species composition of algal/cyanobacterial samples (see Ziegmann et al. (2010)). Five different wavelengths were used by Beutler et al. (1998) in order to mathematically estimate the composition based on the antenna pigments of the five main groups of algae, with further studies building from those findings (Beutler et al. 2003, Beutler et al. 2002, Gregor and Maršálek 2004). Some studies have found that this approach underestimates cyanobacterial concentrations under certain conditions (Pemberton et al. 2007). Other in-situ multi-wavelength fluorometric devices have been proposed (Beutler et al. 2002, Richardson et al. 2010). Using several wavelengths covering the excitation spectra for the main pigments present in major groups of phytoplankton can be suitable to monitor natural phytoplankton communities which have variable composition spatially and temporally (Gregor and Maršálek 2004); however, if focusing on cyanobacteria only, production of PC and other pigments is affected by several factors, such as nutrients and light, so these spectra could be expected to differ with spatial-temporal variations (Beutler et al. 2002). This implies that more work is necessary to compensate the readings for these factors and make such probes more reliable. Additionally, in-situ instrumentation to simultaneously measure the 
parameters causing the variability (e.g. water temperature, turbidity, etc.) would be required to correct the readings.

Fluorescence synchronous scans (SyncScans) were used by Ziegmann et al. (2010) as an alternative, faster, on-line method, to determine whether the age of cyanobacteria affects the fluorescence spectrum. The downside of using specific wavelengths is that certain cyanobacterial pigments have maxima at slightly varying wavelengths, often varying with the age of the cells (Ziegmann et al. 2010). There is, in fact, evidence that some signal overlaps can occur at wavelengths > $660 \mathrm{~nm}$ (Seppälä et al. 2007). Furthermore the peak wavelength of the PC emission spectrum seems to vary slightly based on species (Beutler et al. 2003, Beutler et al. 2002, Gregor et al. 2007, Seppälä et al. 2007). This is because the spectroscopic properties change based on the cellular content and abundance of phycobiliproteins, and the number and type of phycobilin chromophores (Seppälä et al. 2007).

Some probes are more effective at dealing with the issue of pigment wavelength variability than others, due to a broad wavelength bypass (e.g. 640-680 nm). The downside of this is that it can lead to greater incidence of interferences and false positives, as described below (Section 4). The selection of the optimal optical window is therefore challenging. Spectral studies with pure cultures or representative cyanobacterial species should be performed before defining the optimal optical window for a certain location and/or purchasing a particular commercial probe (Seppälä et al. 2007). This approach was used by Zhou et al. (2016) to determine the optimal wavelength for a particular cyanobacterial research application.

Flow cytometers can provide estimates of cell counts as well as morphology of different algal species, and some of these can be used in-situ (Dennis et al. 2011, Pomati et al. 2011, Pomati et al. 2013). Flow cytometers, combined with fluorescence excitation spectra, have been considered as a potential means for rapidly distinguishing between different algal groups (Hilton et al. 1989). Additionally, recently microflow cytometers have been developed (Hashemi et al. 2011), as well as prototype devices combining a microflow cytometer and a multi-channel fluorometer, to allow for distinction between cyanobacteria and other algal phyla by exciting them at different wavelengths (Zieger 2015). Another opportunity consists of modifying current spectrofluorometers for flow-through applications, but they are rarely available or used, as they are currently not sufficiently sensitive, nor robust or cheap (Seppälä et al. 2007).

\section{$4 \quad$ Fluorescence measurement limitations}

Given that chl-a and PC emission wavelengths are similar (685 and $650 \mathrm{~nm}$ respectively) for probes with a broad wavelength bypass (e.g. $\pm 20 \mathrm{~nm}$ ), this might cause false detections of cyanobacterial cells (see Zamyadi et al. (2016a)). This has been deemed to be the main source of interference by some studies (Zamyadi et al. 2016a), but negligible by others (Bowling et al. 2013). Narrower bandwidths would be required; this can be achieved by using higher quality sensor materials for the sensors' glass and filters, which however are associated with higher costs (McBride and Rose in press). A simultaneous monitoring of eukaryotic algal fluorescence could help deal with the spectra overlap (Gregor et al. 2007), and the development of ad-hoc instrumentation with different excitation wavelengths could help to account for interference due to eukaryotic algae (Asai et al. 2001).

Studies using a submersible fluorescence PC probe have also shown that turbidity $>50$ NTU can make fluorescence in-situ PC measurements ineffective (Bowling et al. 2013). Turbidity is typically due to a combination of algae and non-algal suspended particles, hence a proper calibration model accounting for the interaction between the two variables is needed (Bowling et al. 2013). The causal agent of the 
turbidity is also to understand as different sources have different levels of interference with fluorescence readings. For example, in a previous study where sieved soil of a specific different grain size was gradually added to a cyanobacterial culture, small particles $(\leq 0.1 \mathrm{~mm})$ decreased the fluorescence reading by $12.3 \%$ at a concentration of $0.1 \mathrm{~g} / \mathrm{L}$, while large particles $(0.3 \mathrm{~mm})$ reduced the reading by less than one-half, to 5.9\%, at the same concentration (Brient et al. 2008). In general, simultaneous measurement of PC, chl-a and turbidity is recommended in order to account for these errors (Gregor and Maršálek 2004) and allow for the development of real-time compensation models.

Cyanobacterial colonies can emit less fluorescence per cell than solitary cells because the probe excitation beam does not access cells in the inner regions of the colony, and because of scattering of light (Bowling et al. 2013, Gregor and Maršálek 2004, Hodges 2016a). Large colonies might also lead to noisy fluorescence signals and broader confidence levels (Seppälä et al. 2007). This was demonstrated with Microcystis colonies (Chang et al. 2012), although in other studies (McQuaid et al. 2011) it was stated that in vivo PC fluorescence might overestimate cyanobacterial abundance when biovolumes are high. Some studies have found that a better correlation between PC fluorescence and biomass could be achieved at higher rather than lower cyanobacterial concentrations (Gregor et al. 2007). In order to avoid saturation of the PC fluorescence signal during blooms, researchers have experimented with technological modifications to the probe; for instance Brient et al. (2008) have fitted a shutter to reduce the probe's emitted signal, and thus increased the fluorescence signal by six times without affecting linearity. However, there has been little work to specifically examine the effect of colonial cyanobacterial on fluorescence measurements (Hodges 2016a).

Species morphology may also lead to a heterogeneous distribution of cells (Hodges 2016a) causing inaccuracies in the results. Ultrasonic devices, coupled with fluorometers, have been proposed as a mechanism to disaggregate colonies, and bring about a relatively homogeneous cell distribution (Bastien et al. 2011). Additionally, PC can be produced from lysis of cyanobacterial cells, or from cyanobacterial picoplankton not identified by microscopy (Brient et al. 2008). This may explain why fluorescence probe readings may be better correlated with species with larger cell sizes compared with smaller ones (Bowling et al. 2016). Some tools, such as microflow cytometers, are able to detect and characterize picoplankton (Hashemi et al. 2011) and thus could potentially be used in combination with conventional PC fluorescence probes to correct the readings of the latter.

A number of correction techniques have been proposed for certain fluorescence PC probes (Zamyadi et al. (2016a). They include a correction for biases due to chl-a resulting from other phytoplankton, and turbidity when estimating the abundance of a specific species (Microcystis aeruginosa) (Chang et al. 2012, Zamyadi et al. 2012). Additionally, corrections can be made for variations in cyanobacterial biovolume, cellular agglomeration and particle size, assuming spherical colonies and uniformly distributed cells (Chang et al. 2012). By applying these models together the error was reduced by over 90\% (Zamyadi et al. 2016a). In addition, the sensor manuals for the same probe stated that (1) $1 \mathrm{ng} \mathrm{L}^{-1}$ of chl-a causes an interference of 77 cells mL $\mathrm{m}^{-1}$ of falsely detected cyanobacteria, and (2) for each NTU of turbidity (i.e. non-fluorescent particles), the related scattering effect would be equivalent to 21 cells (Zamyadi et al. 2016a). However, this very precise specification appears to oversimplify the quantification of such interferences, as these, for instance, would be likely dependent on cyanobacteria species and the composition relating to agents generating turbidity.

Other sources of interference include water temperature, with warmer waters reducing fluorescence (Hodges 2016a), and the presence of benthic algae (Zamyadi et al. 2012) which are reportedly difficult to quantify (Watson et al. 2016). There are, however, certain probes suitable for detection of benthic algae (Brient et al. 2008). In terms of boundary effects, it is also important to account for a potential 
decrease in signal next to a boundary, i.e., bottom or sides of bottles. This effect has been identified in previous work (Brient et al. 2008), although in other studies, sediments did not create interferences (Hodges 2016a). Coloured dissolved organic matter (cDOM) with similar fluorescence properties to PC and chl-a can also interfere with analyses (Millie et al. 2010), greatly increasing the light attenuation in the water column (Kostoglidis et al. 2005) and thus in turn affecting pigment yields. The presence of humic substances can also create a fluorescence output causing an over-estimation of chl-a, especially when chl-a concentrations are low (Gregor and Maršálek 2004). Other studies have reported that interferences with DOM lead to severe quenching of phycobiliprotein fluorescence (Korak et al. 2015), requiring modelling of nonlinear relationships between concentrations and fluorescence. Wang et al. (2015) demonstrated that some DOM components (specifically, protein-like compounds) can be quenched by other DOM components (humic-like compounds), making it difficult to quantify and account for this effect. Some of the existing multi-wavelength fluorescence probes have, however, incorporated diodes emitting light around the $370 \mathrm{~nm}$ value, in order to excite, and automatically adjust for, the presence of DOM (Gregor and Maršálek 2004).

Irradiance affects the so called fluorescence quenching and is associated with a reduction of the maximum fluorescence yield. For instance, the ratio between fluorescence and chl-a could present a variation as high as 10-fold when in-vivo fluorescence measurements are normalised to concentrations of extracted chl-a (as explained in Sackmann et al. (2008) who based the variation estimate on previous studies). In in-vivo experiments, fluorescence variations can occur due to different mechanisms, complicating a straightforward assessment (Schreiber et al. 1995). Two types of fluorescence quenching exist, being (1) photochemical, and (2) non-photochemical fluorescence (Sackmann et al. 2008, Schreiber et al. 1995). The latter represents, in general terms, the decrease in fluorescence quantum yield (Sackmann et al. 2008). The systematic reduction of fluorescence signal vs chl-a ratio with high solar radiation can be generally termed as daytime fluorescence quenching; such fluorescence signal reduction can be as high as $80 \%$ in surface waters in summer and can be present at depths greater than $50 \mathrm{~m}$ in coastal waters (Sackmann et al. 2008). Interestingly, Sackmann et al. (2008) found correlations between quenching and solar radiation very similar to relationships from previous research conducted elsewhere. This means that there would be potential for the development of a "universal" compensation model to account for this phenomenon.

\section{$5 \quad$ Estimating the proportion of different cyanobacteria species}

Techniques and algorithms need to be developed to estimate the composition and quantity of different groups of algae, or more specifically, between different cyanobacteria species in field samples (Millie et al. 2010) and as part of sediment cores (Kpodonu et al. 2016), because PC sensors per se cannot provide insight into cyanobacterial species differentiation or toxin content (Bastien et al. 2011, Izydorczyk et al. 2005). Algorithms, such as three-way principal component analysis, have previously been used to determine algal groups (Henrion et al. 1997), where five mono-species cultures were used, representative of the different main groups of phytoplankton (i.e. chrysophytes, cryptophytes, chlorophytes, diatoms and cyanobacteria). However, the analysis was based on excitation-emission matrices from data collected with laboratory instrumentation. Two decades ago, the computer program CHEMTAX was developed to estimate the relative abundance of certain algal groups based on measurement of chl-a and other carotenoid pigments using wavelengths in the visible spectrum, high performance liquid chromatography (HPLC) (Mackey et al. 1996) and factor analysis. This was reapplied in later studies (Pinckney et al. 2001). This method is more accurate than field-based methods, but time consuming, and relies on good-quality data and consistent ratios between pigments. CHEMTAX was based on previous work where phytoplankton classes were estimated from specific ratios between chl-a and other pigments, through multiple regression analysis (Everitt et al. 1990, 
Gieskes et al. 1988). This continues to be a widely used method throughout the world but cannot be applied to data collected remotely from sensors, as it relies on HPLC and spectrophotometric detectors.

More recently, different algal phyla have been characterised spectrally, and a prototype monitoring tool, working at different wavelengths (initially, 12 LEDs, to excite all of the most important algal pigments) was developed. It is able to distinguish the presence of cyanobacteria compared to different algal phyla, following principal component analysis (Zieger 2015). In this case, several pigments were considered in order to characterize each algal phyla, given the ability of the sensor to work at several wavelengths and excite each specific pigment. The use of this technique requires the deployment of monochromatic light to avoid the excitation of multiple pigments at the same time (Zamyadi et al. 2016a, Zieger 2015), and as a consequence this can lead to the underestimation of pigment content, especially due to the potential for variations in fluorescence peaks between different phyla or even species, as mentioned previously.

If the focus is only on cyanobacteria, a simpler approach can be developed that relies only on the PC reading, through a risk assessment/scenario analysis approach. In this case the PC reading is transformed into hypothetical cell counts of different cyanobacterial species, based on PC cell quota estimates found in the literature (van der Linden et al. 2017). Despite the fact that the method does not directly infer the species present in the sample, it deploys a "worst-case scenario" approach, providing an early warning trigger of the need for more intensive monitoring. The PC cell quota estimate still needs to take into account the background environmental conditions since, as described above, these affect pigment content.

\section{$6 \quad$ Predicting taste and odour, and toxicity risk}

Although the main purpose of fluorescence probe readings is to trigger monitoring and management actions based on estimated cell counts, there is potential to use them also for the estimation of taste and odour (T\&O), or toxin production risk (Zamyadi et al. 2016a). For example, if the likelihood of the presence of different cyanobacteria species could be estimated, models could then be developed to link the number of cells with the toxin (or T\&O) cell quota values (Zamyadi et al. 2016a). In their review, Watson et al. (2016) provided a list of the estimated geosmin and 2-Methylisoborneol (MIB) production per cell of different cyanobacterial species, also citing several studies outlining how such production is itself affected by factors such as light, temperature or nutrients (see also Rohrlack et al. (2008); Li et al. (2012), Su et al. (2015)). Geosmin production has also been linked both positively and negatively to chl-a production, as outlined in Watson et al. (2016). It is known that geosmin is produced mostly by Nostocales and Oscillatoriales species, while MIB is produced by some Oscillatoriales (Chapman 2010), although less than $3 \%$ of known cyanobacteria species have been confirmed to be able to produce MIB and/or geosmin (American Water Works Association 2011).It should also be acknowledged that $\mathrm{T} \& \mathrm{O}$ is also produced by a range of bacterial species, which can confound estimates based on fluorescence (e.g. Jørgensen et al. (2016)).

Previous studies linked the fluorescence intensity recorded by an in-situ PC probe to the T\&O compound levels (especially MIB) caused by Pseudanabaena (Zamyadi et al. 2016b). Similarly, other studies linked the production of geosmin and MIB to specific cyanobacteria species and noted a correlation between $\mathrm{T} \& \mathrm{O}$ peaks and spikes in PC signal as measured by an in-situ fluorescence probe for total algae (Bertone and O'Halloran 2016). These correlations would change remarkably in cases where the dominant species changes or where there is a mixture of different species with different $T \& O$ production yields. Thus the development of a $\mathrm{T} \& \mathrm{O}$ predictive model based on fluorescence readings should rely on a cyanobacterial species prediction model, and on $T \& O$ concentration data for different 
species; unless site-specific models are developed that are predicated upon the assumption that the same dominant cyanobacterial species are present at any given point in time.

In terms of cyanobacterial toxin content, Ziegmann et al. (2010) linked the amount of toxins produced and released by a laboratory culture of Microcystis aeruginosa to different stages of growth using different maxima of a fluorescence excitation-emission matrix. They found that a signal at wavelengths of $315 \mathrm{~nm}$ (excitation) and $396 \mathrm{~nm}$ (emission), i.e. presumably protein-like substances, may be a useful indicator of cyanobacterial toxin levels. It may be difficult, however, to correctly measure the proteinlike DOM due to quenching effects by other DOM components (Wang et al. 2015). Other studies have not been able to successfully correlate concentrations of cyanotoxins and cyanobacterial biovolume to in vivo PC fluorescence (Bastien et al. 2011). Additional complications in the development of a toxin prediction model for a reservoir are that: (1) toxin production is related to the species and in particular to the cell size (Hawkins et al. 2001); (2) strains vary in their toxin cell quotas, e.g. Cylindrospermopsis raciborskii (Willis et al. 2016); (3) nutrients such as nitrogen and phosphorus differentially affect the growth of toxic and non-toxic strains of cyanobacteria (Vézie et al. 2002); and (4) the breakdown rate of toxins can be influenced by depth-specific factors such as light, water temperature, salinity, nutrients or oxygen (Everson et al. 2009, Everson et al. 2011), and thus changes in depth may lead to decoupling between cyanobacteria concentrations and toxin concentrations.

Both toxins and $\mathrm{T} \& \mathrm{O}$ compounds are components of algogenic organic matter (AOM). AOM is typically released by certain species of cyanobacteria and other algae as a by-product of photosynthesis (Pivokonsky et al. 2016), and its composition depends in turn on growth phase, species, age, and nutrient status (Henderson et al. 2008, Kong et al. 2014, Leloup et al. 2013). In general, the presence of AOM is difficult to quantify as it is typically much lower than the background DOM (Wert et al. 2014). Hence it has been suggested that variations in fluorescent DOM readings could help in understanding AOM release (Korak et al. 2015), provided the remaining DOM amount does not change.

\section{$7 \quad$ Discussion}

Figure 1 schematically summarises the findings of this review by representing how both the measured pigment readings, using either fluorescent probes or measured pigment amounts, are affected by a number of environmental variables that either cause interference or change the yield. Interestingly, cyanobacteria concentration and species greatly affect both the actual pigment concentrations, and the ability to correctly monitor them with fluorescent probes. 


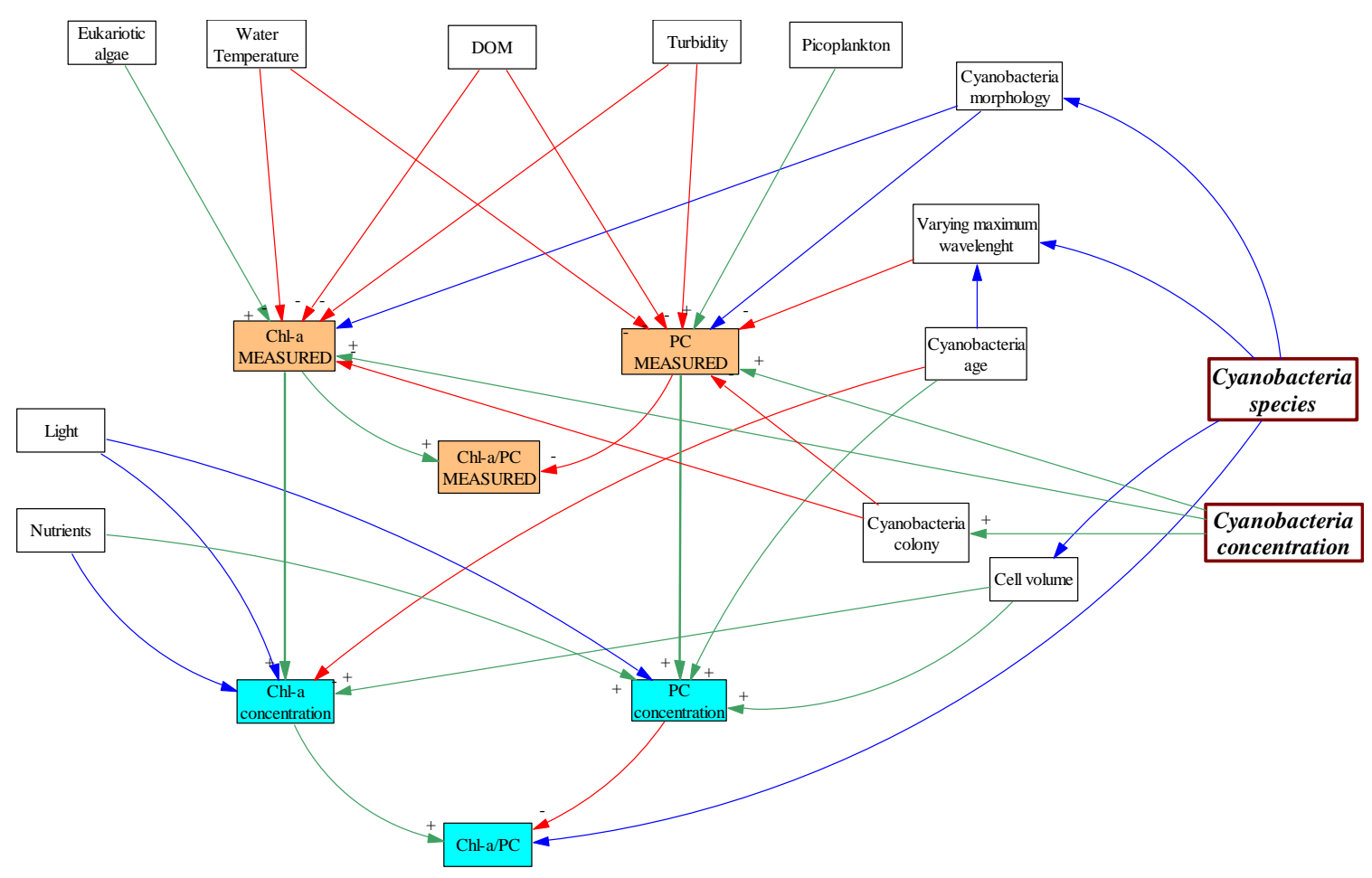

Figure 1 - A summary of parameters affecting chl-a and PC concentrations and their measurements. Green arrows indicate that the input positively affects the output (i.e., an increase in the input value implies an increase in the output value), red arrows imply that the input negatively affects the output (i.e., an increase in the input value implies a decrease in the output value), and blue arrows represent an unspecified link (i.e., there is insufficient, or contrasting, evidence in the literature regarding the way the input affects the output).

In-situ PC fluorometry has been recommended as a cyanobacterial bloom management tool in certain regions of the world, e.g. Australian locations (NSW Office of Water 2012). Importantly, several factors can affect the accuracy and reliability of in-situ fluorescence probes, and a large body of research work has been conducted globally to quantify the effects of a number of these parameters. However, no study has yet been conducted which simultaneously quantifies the effects of most, if not all, of these variables to enable to correct measured chlorophyll and PC fluorescence values, and in turn quantify abundance and species of cyanobacteria. If such a comprehensive dataset can be developed, there would be potential to develop a predictive model providing the probability of having different cyanobacteria species in a reservoir, based on corrected readings of commercially available in-situ fluorescent PC and chl-a probes. To increase accuracy, such a model could also rely on other regularly monitored data (e.g. water temperature, nutrients, time of the year) and site-specific historical data of cyanobacterial species prevalence under different environmental conditions. A large amount of research work has been undertaken around the world to predict cyanobacteria blooms (which is out of the scope of this review - for information see e.g. Oliver et al. (2012)), and thus this knowledge and historical site-specific data could be incorporated in the proposed model.

In recent decades, artificial intelligence has been used in several applications, especially in the water industry, to solve complex problems. Modelling techniques, such as artificial neural networks, have been extensively applied and have enabled the optimization of water resource management (Maier and Dandy 2000), while a variety of data-driven or hybrid models have been developed to leverage remote 
sensors and historical data by achieving water treatment operation optimisation and cost savings (Bertone et al. 2015, Bertone et al. 2016b).

Pattern recognition is another technique which would also potentially suit the proposed research goal, as it could enable the decomposition of a "signal" (i.e. total chl-a and PC measurements of a field sample) into chl-a and PC contributions from different species. An early application of pattern recognition for classification of different phytoplankton species (including cyanobacteria) is represented by the work of Embleton et al. (2003), with the models able to classify the four different predominant species of a Northern Ireland lake, based on microscopy images of the samples. A very similar modelling attempt was performed later by Mosleh et al. (2012). Similarly, CHEMTAX represents an early attempt at algal class level classification; but it does not rely on in-situ fluorescence probes or fully account for interferences. Based on this review, it is argued that artificial intelligence approaches combined with a well-designed set of experiments and a large amount of site-specific historical data, would allow the development of a similar model, but that may further allow classification of cyanobacteria species based on in-situ data only (Figure 2).

Bayesian Networks (Fenton and Neil 2008) are also commonly used for risk assessment and analysis and have been also widely deployed in the water resource management area (Bertone et al. 2016a, Castelletti and Soncini-Sessa 2007). There are applications in the cyanobacterial bloom management field (Johnson et al. 2010). Bayesian Networks represent a modelling candidate for this research problem due to their ability to deal with missing data and uncertainty, through the use of conditional probabilities and the integration of experts' opinion into the network (Chen and Pollino 2012, Uusitalo 2007). Outputs from other models that can provide insights on the mechanisms causing and governing blooms (e.g. Wallace and Hamilton (2000)) can also be incorporated. Although Bayesian Networks have been applied to determine the probability of cyanobacterial blooms (Hamilton et al. 2007, Rigosi et al. 2015), they have not been developed in order to predict the likelihood of the presence of different, distinct algal groups or cyanobacteria species based on sensor data.

The entropy theory, specifically maximum entropy modelling, could also be used for this purpose. In simple terms, the principle of maximum entropy states that, among a number of potential combinations of modelling outputs satisfying all a system's constraints, the best solution is the one maximising the Shannon entropy (Jaynes 1957). In terms of cyanobacterial species classification, it can be seen that a number of solutions (e.g. probability and numbers of different species) would exist that satisfy the same set of constraints (e.g. sum of species-specific PC signals must equal the total PC signal as per probe reading). Hence, maximum entropy modelling would facilitate the identification of the true solution. Entropy theory has been applied to several environmental and water resource problems (Singh 2000). For instance, Tanyimboh and Sheahan (2002) used maximum entropy principles to identify the best water distribution system design in order to optimise the balance of cost and reliability. Another example is given by Lee and Wentz (2008), who used a Bayesian Maximum Entropy approach to assimilate soft data and better predict spatial water use variability. However, there is limited evidence of applications in the water quality field, and in particular for cyanobacteria prediction or management.

In conclusion, all the proposed modelling approaches are valuable options in achieving the goal of datadriven cyanobacterial species classification prediction; the optimal model can be selected based on features of available data, or from a direct comparison of prediction accuracy over a test set of data. Regardless of the model choice it is evident that modelling options exist to potentially achieve such research goals. 


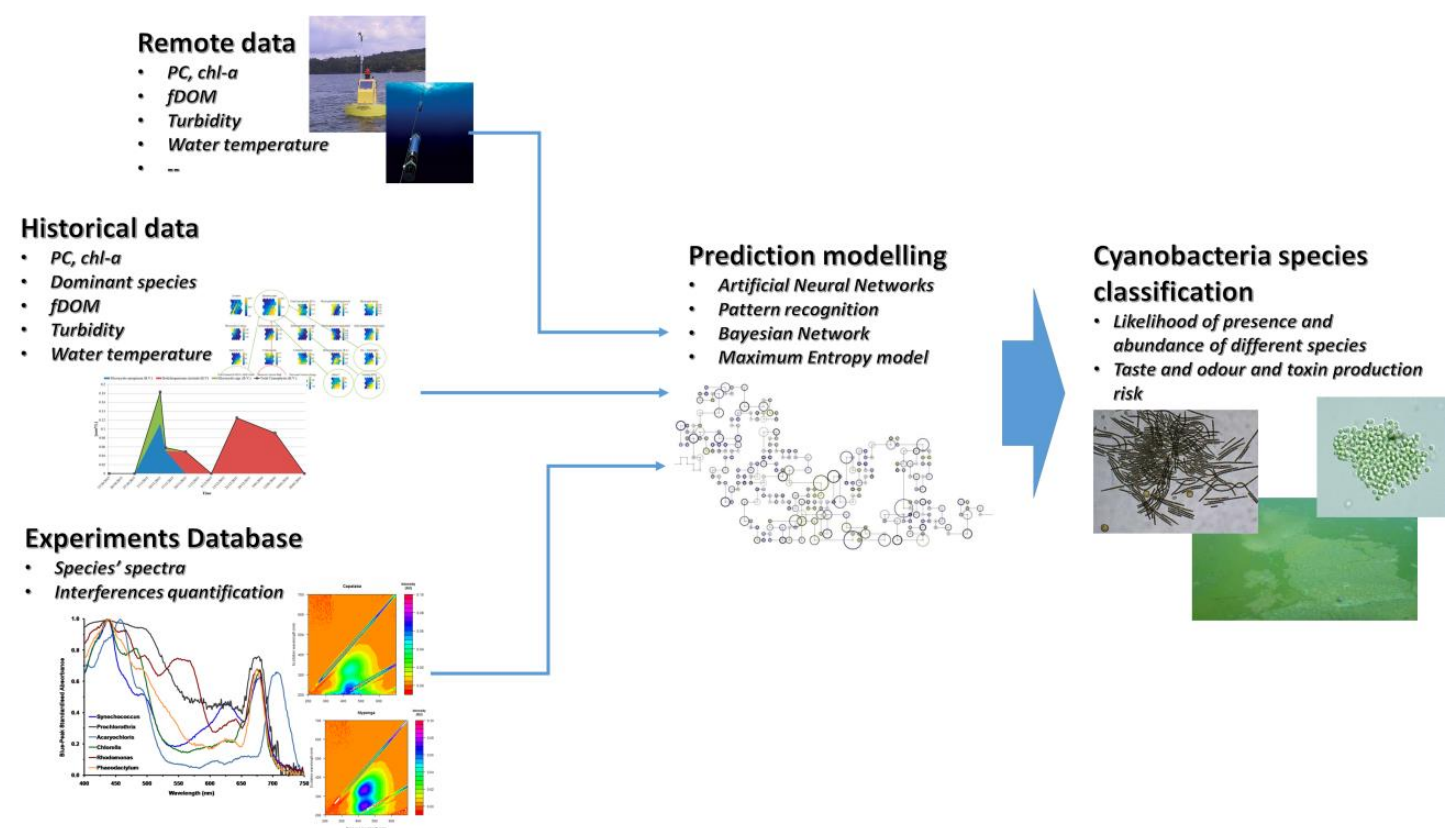

Figure 2 - Graphical conceptual representation of a cyanobacterial species classification model

\section{$8 \quad$ Conclusions}

In this review paper we identified both impediments and opportunities for using online remote fluorescence probes for accurate and reliable monitoring of cyanobacteria in reservoirs. The technology has become cheaper and more accessible over time, but we have highlighted a number of environmental and technological impediments affecting the reliability of probe readings. We argue that unless these interferences and variability in pigment production are accounted for in a comprehensive calibration model, many of these probes provide unreliable information about cyanobacterial densities or biovolume, and little or no information about species.

On the other hand, research has shown that it is possible, in most cases, to quantify how those variables and processes affect the estimation of cyanobacterial species and abundance. Starting from a specific location, it is possible to conduct experiments to calibrate the readings to most of the conditions at that location. In addition, there is potential to use such experimental outputs, combined with literature data, as inputs to a complex predictive model. This would potentially combine pattern recognition algorithms and Bayesian Networks, to provide the likelihood of occurrence and biomass estimates of different cyanobacterial species, based on real-time fluorescence probe readings and other remotely collected data. Based on the predicted species, the risk of toxins, or taste and odour compound concentrations could also be estimated, thus assisting water resource managers and operators to be more effective and proactively manage cyanobacteria-related issues related to recreational and drinking water.

\section{Acknowledgements}

This research did not receive any specific grant from funding agencies in the public, commercial, or not-for-profit sectors.

\section{References}


Allan, M.G., Hamilton, D.P., Hicks, B.J. and Brabyn, L. (2011) Landsat remote sensing of chlorophyll a concentrations in central North Island lakes of New Zealand. International Journal of Remote Sensing 32(7), 2037-2055.

Alpine, A.E. and Cloern, J.E. (1985) Differences in in vivo fluorescence yield between three phytoplankton size classes. Journal of Plankton Research 7(3), 381-390.

American Water Works Association (2011) Algae: source to treatment, American Water Works Association.

Asai, R., Horiguchi, Y., Yoshida, A., McNiven, S., Tahira, P., Ikebukuro, K., Uchiyama, S., Masuda, Y. and Karube, I. (2001) Detection of phycobilin pigments and their seasonal change in Lake Kasumigaura using a sensitive in situ fluorometric sensor. Analytical Letters 34(14), 2521-2533.

Bastien, C., Cardin, R., Veilleux, É., Deblois, C., Warren, A. and Laurion, I. (2011) Performance evaluation of phycocyanin probes for the monitoring of cyanobacteria. Journal of Environmental Monitoring 13(1), 110-118.

Bertone, E. and O'Halloran, K. (2016) Analysis and Modelling of Taste and Odour Events in a Shallow Subtropical Reservoir. Environments 3(3), 22.

Bertone, E., Sahin, O., Richards, R. and Roiko, A. (2016a) Extreme events, water quality and health: A participatory Bayesian risk assessment tool for managers of reservoirs. Journal of Cleaner Production $135,657-667$.

Bertone, E., Stewart, R.A., Zhang, H., Bartkow, M. and Hacker, C. (2015) An autonomous decision support system for manganese forecasting in subtropical water reservoirs. Environmental Modelling \& Software 73, 133-147.

Bertone, E., Stewart, R.A., Zhang, H. and O'Halloran, K. (2016b) Hybrid water treatment cost prediction model for raw water intake optimization. Environmental Modelling \& Software 75, 230-242.

Beutler, M., Wiltshire, K., Meyer, B. and Moldaenke, C. (1998) Differentiation of spectral groups of algae with computer-based analysis of fluorescence excitation spectra. Vom Wasser 91, 61-74.

Beutler, M., Wiltshire, K.H., Arp, M., Kruse, J., Reineke, C., Moldaenke, C. and Hansen, U.P. (2003) A reduced model of the fluorescence from the cyanobacterial photosynthetic apparatus designed for the in situ detection of cyanobacteria. Biochimica et Biophysica Acta (BBA) - Bioenergetics 1604(1), 3346.

Beutler, M., Wiltshire, K.H., Meyer, B., Moldaenke, C., Lüring, C., Meyerhöfer, M., Hansen, U.-P. and Dau, H. (2002) A fluorometric method for the differentiation of algal populations in vivo and in situ. Photosynthesis Research 72(1), 39-53.

Bowling, L., Ryan, D., Holliday, J. and Honeyman, G. (2013) Evaluation of in situ fluorometry to determine cyanobacterial abundance in the Murray and Lower Darling Rivers, Australia. River Research and Applications 29(8), 1059-1071.

Bowling, L.C., Zamyadi, A. and Henderson, R.K. (2016) Assessment of in situ fluorometry to measure cyanobacterial presence in water bodies with diverse cyanobacterial populations. Water Research 105, $22-33$.

Brient, L., Lengronne, M., Bertrand, E., Rolland, D., Sipel, A., Steinmann, D., Baudin, I., Legeas, M., Le Rouzic, B. and Bormans, M. (2008) A phycocyanin probe as a tool for monitoring cyanobacteria in freshwater bodies. Journal of Environmental Monitoring 10(2), 248-255. 
Bryant, D.A. (1982) Phycoerythrocyanin and phycoerythrin: properties and occurrence in cyanobacteria. Microbiology 128(4), 835-844.

Bryant, D.A. (2006) The molecular biology of cyanobacteria, Springer Science \& Business Media.

Carmichael, W.W. (2001) Health effects of toxin-producing cyanobacteria:“The CyanoHABs". Human and ecological risk assessment: An International Journal 7(5), 1393-1407.

Castelletti, A. and Soncini-Sessa, R. (2007) Bayesian Networks and participatory modelling in water resource management. Environmental Modelling \& Software 22(8), 1075-1088.

Chang, D.-W., Hobson, P., Burch, M. and Lin, T.-F. (2012) Measurement of cyanobacteria using invivo fluoroscopy - Effect of cyanobacterial species, pigments, and colonies. Water Research 46(16), 5037-5048.

Chapman, A.D. (2010) Algae: Source to Treatment. American Water Works Association (ed), pp. 125142.

Chen, S. and Pollino, C. (2012) Good practice in Bayesian network modelling. Environmental Modelling \& Software 37, 134-145.

DELWP Biovolume Calculator $\quad$ Sheet.

https://www.water.vic.gov.au/ data/assets/excel doc/0027/65592/BIOVOLUME-

CALCULATOR.XLSX, Environmental Health Unit, Department of Human Services, Victoria.

Dennis, M., Landman, M., Wood, S.A. and Hamilton, D. (2011) Application of flow cytometry for examining phytoplankton succession in two eutrophic lakes. Water Science and Technology 64(4), 9991008 .

Embleton, K., Gibson, C. and Heaney, S. (2003) Automated counting of phytoplankton by pattern recognition: a comparison with a manual counting method. Journal of Plankton Research 25(6), 669681.

Erickson, J.S., Hashemi, N., Sullivan, J.M., Weidemann, A.D. and Ligler, F.S. (2011) In situ phytoplankton analysis: there's plenty of room at the bottom. Analytical chemistry 84(2), 839-850.

Everitt, D., Wright, S., Volkman, J., Thomas, D. and Lindstrom, E. (1990) Phytoplankton community compositions in the western equatorial Pacific determined from chlorophyll and carotenoid pigment distributions. Deep Sea Research Part A. Oceanographic Research Papers 37(6), 975-997.

Everson, S., Fabbro, L., Kinnear, S., Eaglesham, G. and Wright, P. (2009) Distribution of the cyanobacterial toxins cylindrospermopsin and deoxycylindrospermopsin in a stratified lake in northeastern New South Wales, Australia. Marine and Freshwater Research 60(1), 25-33.

Everson, S., Fabbro, L., Kinnear, S. and Wright, P. (2011) Extreme differences in akinete, heterocyte and cylindrospermopsin concentrations with depth in a successive bloom involving Aphanizomenon ovalisporum (Forti) and Cylindrospermopsis raciborskii (Woloszynska) Seenaya and Subba Raju. Harmful Algae 10(3), 265-276.

Fenton, N. and Neil, M. (2008) Risk assessment and decision analysis with Bayesian Networks, CRC Press, Taylor \& Francis Group, Boca Raton, FL, USA.

Gieskes, W., Kraay, G., Nontji, A., Setiapermana, D. and Sutomo (1988) Monsoonal alternation of a mixed and a layered structure in the phytoplankton of the euphotic zone of the Banda Sea (Indonesia): a mathematical analysis of algal pigment fingerprints. Netherlands Journal of Sea Research 22(2), 123 137. 
Gregor, J. and Maršálek, B. (2004) Freshwater phytoplankton quantification by chlorophyll a: a comparative study of in vitro, in vivo and in situ methods. Water Research 38(3), 517-522.

Gregor, J., Maršálek, B. and Šípková, H. (2007) Detection and estimation of potentially toxic cyanobacteria in raw water at the drinking water treatment plant by in vivo fluorescence method. Water Research 41(1), 228-234.

Hamilton, D.P., Carey, C.C., Arvola, L., Arzberger, P., Brewer, C., Cole, J.J., Gaiser, E., Hanson, P.C., Ibelings, B.W. and Jennings, E. (2015) A Global Lake Ecological Observatory Network (GLEON) for synthesising high-frequency sensor data for validation of deterministic ecological models. Inland Waters 5(1), 49-56.

Hamilton, G.S., Fielding, F., Chiffings, A.W., Hart, B.T., Johnstone, R.W. and Mengersen, K. (2007) Investigating the use of a Bayesian network to model the risk of Lyngbya majuscula bloom initiation in Deception Bay, Queensland, Australia. Human and Ecological Risk Assessment 13(6), 1271-1287.

Hashemi, N., Erickson, J.S., Golden, J.P., Jackson, K.M. and Ligler, F.S. (2011) Microflow Cytometer for optical analysis of phytoplankton. Biosensors and Bioelectronics 26(11), 4263-4269.

Hawkins, P.R., Putt, E., Falconer, I. and Humpage, A. (2001) Phenotypical variation in a toxic strain of the phytoplankter, Cylindrospermopsis raciborskii (Nostocales, Cyanophyceae) during batch culture. Environmental Toxicology 16(6), 460-467.

Henderson, R.K., Baker, A., Parsons, S.A. and Jefferson, B. (2008) Characterisation of algogenic organic matter extracted from cyanobacteria, green algae and diatoms. Water Research 42(13), 34353445.

Henrion, R., Henrion, G., Böhme, M. and Behrendt, H. (1997) Three-way principal components analysis for fluorescence spectroscopic classification of algae species. Fresenius' Journal of Analytical Chemistry 357(5), 522-526.

Hilton, J., Rigg, E. and Jaworski, G. (1989) Algal identification using in vivo fluorescence spectra. Journal of Plankton Research 11(1), 65-74.

Hodges, C. (2016a) A validation study of phycocyanin sensors for monitoring cyanobacteria in cultures and field samples. Masters of Science (Research) thesis, The University of Waikato.

Hodges, C.M. (2016b) A validation study of phycocyanin sensors for monitoring cyanobacteria in cultures and field samples, University of Waikato.

Hodges, C.M., Wood, S.A., Puddick, J., McBride, C.G. and Hamilton, D.P. (2017) Sensor manufacturer, temperature, and cyanobacteria morphology affect phycocyanin fluorescence measurements. Environmental Science and Pollution Research, 1-10.

Horváth, H., Kovács, A.W., Riddick, C. and Présing, M. (2013) Extraction methods for phycocyanin determination in freshwater filamentous cyanobacteria and their application in a shallow lake. European journal of phycology 48(3), 278-286.

Izydorczyk, K., Tarczynska, M., Jurczak, T., Mrowczynski, J. and Zalewski, M. (2005) Measurement of phycocyanin fluorescenceas an online early warning system for cyanobacteria in reservoir intake water. Environmental Toxicology 20(4), 425-430.

Jaynes, E.T. (1957) Information theory and statistical mechanics. Physical review 106(4), 620.

Johnson, S., Fielding, F., Hamilton, G. and Mengersen, K. (2010) An Integrated Bayesian Network approach to Lyngbya majuscula bloom initiation. Marine Environmental Research 69(1), 27-37. 
Jørgensen, N.O., Podduturi, R. and Burford, M.A. (2016) Relations between abundance of potential geosmin-and 2-MIB-producing organisms and concentrations of these compounds in water from three Australian reservoirs. Journal of Water Supply: Research and Technology-Aqua 65(6), 504-513.

Kong, Y., Lou, I., Zhang, Y., Lou, C.U. and Mok, K.M. (2017) Advances in Monitoring and Modelling Algal Blooms in Freshwater Reservoirs, pp. 45-67, Springer.

Kong, Y., Zhu, L., Zou, P., Qi, J., Yang, Q., Song, L. and Xu, X. (2014) Isolation and characterization of dissolved organic matter fractions from antialgal products of Microcystis aeruginosa. Environmental Science and Pollution Research 21(5), 3946-3954.

Korak, J.A., Wert, E.C. and Rosario-Ortiz, F.L. (2015) Evaluating fluorescence spectroscopy as a tool to characterize cyanobacteria intracellular organic matter upon simulated release and oxidation in natural water. Water Research 68, 432-443.

Kostoglidis, A., Pattiaratchi, C.B. and Hamilton, D.P. (2005) CDOM and its contribution to the underwater light climate of a shallow, microtidal estuary in south-western Australia. Estuarine, Coastal and Shelf Science 63(4), 469-477.

Kpodonu, A.T.N., Hamilton, D.P., Hartland, A., Laughlin, D.C. and Lusk, C.H. (2016) Coupled use of sediment phosphorus speciation and pigment composition to infer phytoplankton phenology over 700 years in a deep oligotrophic lake. Biogeochemistry 129(1-2), 181-196.

Kudela, R.M., Palacios, S.L., Austerberry, D.C., Accorsi, E.K., Guild, L.S. and Torres-Perez, J. (2015) Application of hyperspectral remote sensing to cyanobacterial blooms in inland waters. Remote Sensing of Environment 167, 196-205.

Lee, S.J. and Wentz, E.A. (2008) Applying Bayesian Maximum Entropy to extrapolating local-scale water consumption in Maricopa County, Arizona. Water Resources Research 44(1).

Lee, T.-y., Tsuzuki, M., Takeuchi, T., Yokoyama, K. and Karube, I. (1995) Quantitative determination of cyanobacteria in mixed phytoplankton assemblages by an in vivo fluorimetric method. Analytica Chimica Acta 302(1), 81-87.

Leloup, M., Nicolau, R., Pallier, V., Yéprémian, C. and Feuillade-Cathalifaud, G. (2013) Organic matter produced by algae and cyanobacteria: quantitative and qualitative characterization. Journal of Environmental Sciences 25(6), 1089-1097.

Li, Z., Hobson, P., An, W., Burch, M.D., House, J. and Yang, M. (2012) Earthy odor compounds production and loss in three cyanobacterial cultures. Water Research 46(16), 5165-5173.

MacColl, R. (1998) Cyanobacterial phycobilisomes. Journal of structural biology 124(2), 311-334.

Mackey, M., Mackey, D., Higgins, H. and Wright, S. (1996) CHEMTAX — a program for estimating class abundances from chemical markers: application to HPLC measurements of phytoplankton. Marine Ecology Progress Series, 265-283.

Maier, H.R. and Dandy, G.C. (2000) Neural networks for the prediction and forecasting of water resources variables: a review of modelling issues and applications. Environmental Modelling \& Software 15(1), 101-124.

McBride, C. and Rose, K. (in press) Automated high-frequency monitoring and research. In "Lake Restoration Handbook: A New Zealand Perspective". Hamilton DP, Collier, K., Quinn JM and C, H.W. (eds), Springer. 
McQuaid, N., Zamyadi, A., Prévost, M., Bird, D. and Dorner, S. (2011) Use of in vivo phycocyanin fluorescence to monitor potential microcystin-producing cyanobacterial biovolume in a drinking water source. Journal of Environmental Monitoring 13(2), 455-463.

Millie, D.F., Pigg, R.J., Fahnenstiel, G.L. and Carrick, H.J. (2010) Algae: Source to Treatment. American Water Works Association (ed), pp. 93-114.

Mosleh, M.A., Manssor, H., Malek, S., Milow, P. and Salleh, A. (2012) A preliminary study on automated freshwater algae recognition and classification system, p. S25, BioMed Central.

NSW Office of Water (2012) Evaluation of a YSI fluorometer to determine cyanobacterial presence in the Murray and lower Darling Rivers, p. 65, New South Wales Department of Primary Industries, a division of NSW Department of Trade and Investment, Regional Infrastructure and Services.

O’Neil, J.M., Davis, T.W., Burford, M.A. and Gobler, C.J. (2012) The rise of harmful cyanobacteria blooms: The potential roles of eutrophication and climate change. Harmful Algae 14, 313-334.

Oliver, R.L., Hamilton, D.P., Brookes, J.D. and Ganf, G.G. (2012) Ecology of cyanobacteria II, pp. 155-194, Springer.

Pemberton, K.L., Smith, R.E., Silsbe, G.M., Howell, T. and Watson, S.B. (2007) Controls on phytoplankton physiology in Lake Ontario during the late summer: evidence from new fluorescence methods. Canadian Journal of Fisheries and Aquatic Sciences 64(1), 58-73.

Pinckney, J.L., Richardson, T.L., Millie, D.F. and Paerl, H.W. (2001) Application of photopigment biomarkers for quantifying microalgal community composition and in situ growth rates. Organic Geochemistry 32(4), 585-595.

Pivokonsky, M., Naceradska, J., Kopecka, I., Baresova, M., Jefferson, B., Li, X. and Henderson, R. (2016) The impact of algogenic organic matter on water treatment plant operation and water quality: A review. Critical Reviews in Environmental Science and Technology 46(4), 291-335.

Pobel, D., Robin, J. and Humbert, J.-F. (2011) Influence of sampling strategies on the monitoring of cyanobacteria in shallow lakes: Lessons from a case study in France. Water Research 45(3), 1005-1014.

Pomati, F., Jokela, J., Simona, M., Veronesi, M. and Ibelings, B.W. (2011) An automated platform for phytoplankton ecology and aquatic ecosystem monitoring. Environmental science \& technology 45(22), 9658-9665.

Pomati, F., Kraft, N.J., Posch, T., Eugster, B., Jokela, J. and Ibelings, B.W. (2013) Individual cell based traits obtained by scanning flow-cytometry show selection by biotic and abiotic environmental factors during a phytoplankton spring bloom. PloS one 8(8), e71677.

Randolph, K., Wilson, J., Tedesco, L., Li, L., Pascual, D.L. and Soyeux, E. (2008) Hyperspectral remote sensing of cyanobacteria in turbid productive water using optically active pigments, chlorophyll a and phycocyanin. Remote Sensing of Environment 112(11), 4009-4019.

Rapala, J. (1998) Toxin production by freshwater cyanobacteria: effects of environmental factors, Biocenter Viikki Universitatis Helsingiensis.

Richardson, T.L., Lawrenz, E., Pinckney, J.L., Guajardo, R.C., Walker, E.A., Paerl, H.W. and MacIntyre, H.L. (2010) Spectral fluorometric characterization of phytoplankton community composition using the Algae Online Analyser®. Water Research 44(8), 2461-2472. 
Rigosi, A., Hanson, P., Hamilton, D.P., Hipsey, M., Rusak, J.A., Bois, J., Sparber, K., Chorus, I., Watkinson, A.J. and Qin, B. (2015) Determining the probability of cyanobacterial blooms: the application of Bayesian networks in multiple lake systems. Ecological applications 25(1), 186-199.

Rohrlack, T., Edvardsen, B., Skulberg, R., Halstvedt, C.B., Utkilen, H.C., Ptacnik, R. and Skulberg, O.M. (2008) Oligopeptide chemotypes of the toxic freshwater cyanobacterium Planktothrix can form sub-populations with dissimilar ecological traits. Limnology and Oceanography 53(4), 1279-1293.

Sackmann, B., Perry, M. and Eriksen, C. (2008) Seaglider observations of variability in daytime fluorescence quenching of chlorophyll-a in Northeastern Pacific coastal waters. Biogeosciences Discussions 5(4), 2839-2865.

Schopf, J.W. (1996) Cyanobacteria: pioneers of the early Earth. NOVA HEDWIGIA BEIHEFT 112, $13-32$.

Schreiber, U., Endo, T., Mi, H. and Asada, K. (1995) Quenching Analysis of Chlorophyll Fluorescence by the Saturation Pulse Method: Particular Aspects Relating to the Study of Eukaryotic Algae and Cyanobacteria. Plant and Cell Physiology 36(5), 873-882.

Seppälä, J., Ylöstalo, P., Kaitala, S., Hällfors, S., Raateoja, M. and Maunula, P. (2007) Ship-ofopportunity based phycocyanin fluorescence monitoring of the filamentous cyanobacteria bloom dynamics in the Baltic Sea. Estuarine, Coastal and Shelf Science 73(3), 489-500.

Singh, V.P. (2000) The entropy theory as a tool for modeling and decision-making in environmental and water resources.

Sobiechowska-Sasim, M., Stoń-Egiert, J. and Kosakowska, A. (2014) Quantitative analysis of extracted phycobilin pigments in cyanobacteria - an assessment of spectrophotometric and spectrofluorometric methods. Journal of Applied Phycology 26(5), 2065-2074.

Steiner, K., Wood, S.A., Puddick, J., Hawes, I., Dietrich, D.R. and D.P, H. (2017) A Comparison of bacterial community structure, activity and microcystins associated with formation and breakdown of a cyanobacterial scum. Microbial Ecology

Su, M., Yu, J., Zhang, J., Chen, H., An, W., Vogt, R.D., Andersen, T., Jia, D., Wang, J. and Yang, M. (2015) MIB-producing cyanobacteria (Planktothrix sp.) in a drinking water reservoir: Distribution and odor producing potential. Water Research 68, 444-453.

Tanyimboh, T. and Sheahan, C. (2002) A maximum entropy based approach to the layout optimization of water distribution systems. Civil Engineering and Environmental Systems 19(3), 223-253.

Uusitalo, L. (2007) Advantages and challenges of Bayesian networks in environmental modelling. Ecological Modelling 203, 312-318.

van der Linden, L., Courtois, S., Faye, G., Steinmann, D. and Newcombe, G. (2017) Post-processing of phycocyanin probe outputs for better reservoir and water treatment outcomes, Shanghai, China.

Vézie, C., Rapala, J., Vaitomaa, J., Seitsonen, J. and Sivonen, K. (2002) Effect of nitrogen and phosphorus on growth of toxic and nontoxic Microcystis strains and on intracellular microcystin concentrations. Microbial ecology 43(4), 443-454.

Wallace, B.B. and Hamilton, D.P. (2000) Simulation of water-bloom formation in the cyanobacterium Microcystis aeruginosa. Journal of Plankton Research 22(6), 1127-1138.

Wang, Z., Cao, J. and Meng, F. (2015) Interactions between protein-like and humic-like components in dissolved organic matter revealed by fluorescence quenching. Water Research 68, 404-413. 
Waterbury, J.B., Watson, S.W., Guillard, R.R. and Brand, L.E. (1979) Widespread occurrence of a unicellular, marine, planktonic, cyanobacterium [10]. Nature 277(5694), 293-294.

Watson, S.B., Monis, P., Baker, P. and Giglio, S. (2016) Biochemistry and genetics of taste-and odorproducing cyanobacteria. Harmful Algae 54, 112-127.

Wert, E.C., Korak, J.A., Trenholm, R.A. and Rosario-Ortiz, F.L. (2014) Effect of oxidant exposure on the release of intracellular microcystin, MIB, and geosmin from three cyanobacteria species. Water Research 52, 251-259.

Willis, A., Chuang, A.W., Woodhouse, J.N., Neilan, B.A. and Burford, M.A. (2016) Intraspecific variation in growth, morphology and toxin quotas for the cyanobacterium, Cylindrospermopsis raciborskii. Toxicon 119, 307-310.

Zamyadi, A., Choo, F., Newcombe, G., Stuetz, R. and Henderson, R.K. (2016a) A review of monitoring technologies for real-time management of cyanobacteria: Recent advances and future direction. $\operatorname{Tr} A C$ Trends in Analytical Chemistry 85, 83-96.

Zamyadi, A., Henderson, R.K., Stuetz, R., Newcombe, G., Newtown, K. and Gladman, B. (2016b) Cyanobacterial management in full-scale water treatment and recycling processes: reactive dosing following intensive monitoring. Environmental Science: Water Research \& Technology 2(2), 362-375.

Zamyadi, A., McQuaid, N., Dorner, S., Bird, D.F., Burch, M., Baker, P., Hobson, P. and Prevost, M. (2012) Cyanobacterial detection using in vivo fluorescence probes: managing interferences for improved decision-making. Journal-American Water Works Association 104(8), E466-E479.

Zhou, Y., Jeppesen, E., Zhang, Y., Shi, K., Liu, X. and Zhu, G. (2016) Dissolved organic matter fluorescence at wavelength $275 / 342 \mathrm{~nm}$ as a key indicator for detection of point-source contamination in a large Chinese drinking water lake. Chemosphere 144, 503-509.

Zieger, S. (2015) Optical detection module of algae species used as early warning system, Graz University of Technology, Graz.

Ziegmann, M., Abert, M., Müller, M. and Frimmel, F.H. (2010) Use of fluorescence fingerprints for the estimation of bloom formation and toxin production of Microcystis aeruginosa. Water Research 44(1), 195-204. 